\title{
Responsibility to Protect
}

\author{
Ein neuer Ansatz im Völkerrecht zur Verhinderung von Völkermord, \\ Kriegsverbrechen und Verbrechen gegen die Menschlichkeit
}

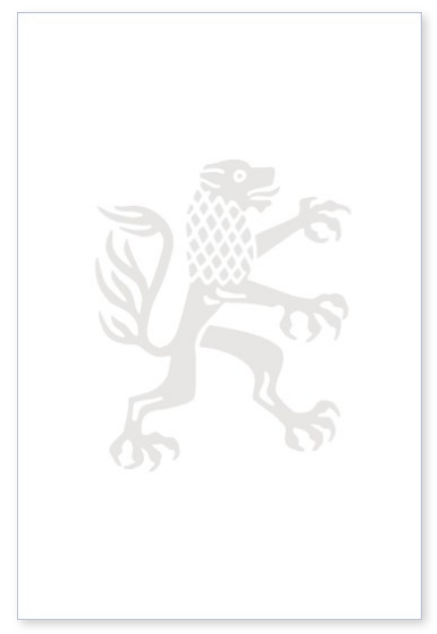

2009. XVIII, 433 Seiten. JusIntEu 29

ISBN 978-3-16-151168-4

DOI 10.1628/978-3-16-151168-4

eBook PDF $94,00 €$
Christopher Verlage geht der Frage nach, ob die von den Vereinten Nationen im Jahr 2005 beschlossene »Responsibility to Protect » der Staatengemeinschaft künftig eine völkerrechtliche Pflicht auferlegt, Völkermord, schwere Kriegsverbrechen und Verbrechen gegen die Menschlichkeit notfalls auch durch militärische Zwangsmaßnahmen zu verhindern. Nach umfangreicher Rechtsquellenauswertung stuft er die »Responsibility to Protect » als neue Norm des Völkerrechts ein und legt dar, dass sich kein Staat mehr auf den Schutzmantel seiner Souveränität und des daraus fließenden Interventionsverbots berufen kann, wenn er unwillens oder unfähig ist, schwerste Missachtungen grundlegender Menschenrechte auf seinem Territorium zu verhindern. Vielmehr geht in einer solchen Situation die Verantwortung zum Schutz der bedrohten fremden Staatsbürger in erster Linie durch den Friedenssicherungsmechanismus der UNO auf die Staatengemeinschaft als Ganzes über. Der Autor zeigt auf, dass die »Responsibility to Protect » den Sicherheitsratsmitgliedern, insbesondere den Vetomächten, einen vorher so nicht da gewesenen Handlungsdruck auferlegt, mit geeigneten und rechtzeitigen Zwangsmaßnahmen gemäß Art. 41 und 42 UNC die Unterbindung von Völkermord, schweren Kriegsverbrechen und Verbrechen gegen die Menschlichkeit zu gewährleisten. Er legt jedoch auch dar, dass sie derzeit noch keine Interventionspflicht der Staatengemeinschaft begründet. Anders verhält es sich aber bezüglich Staaten, die eine besondere Nähebeziehung zur Krisenregion haben und denen Reaktionsmaßnahmen besonders möglich und zumutbar sind. Das Buch wurde mit dem Harry-Westermann-Preis der Rechtswissenschaftlichen Fakultät der Universität Münster ausgezeichnet.

Christopher Verlage Geboren 1981; Studium der Rechtswissenschaft in Münster; 2008 Promotion; wissenschaftlicher Mitarbeiter am Lehrstuhl für Öffentliches Recht, einschließlich Völker- und Europarecht an der WWU Münster; derzeit Rechtsreferendar am OLG Hamm.

Jetzt bestellen:

https://mohrsiebeck.com/buch/responsibility-to-protect-9783161511684?no_cache=1

order@mohrsiebeck.com

Telefon: +49 (0)7071-923-17

Telefax: +49 (0)7071-51104 